\title{
Inter Personal Conflict Resolution Methods on Case of Land in SemadaWerda, South Gonder Ethiopia
}

Abay Bantihun* and Melese Worku

Faculty of Agriculture and Environmental Sciences, Debre Markos University, Deber Tabor, Ethiopia

\begin{abstract}
The study is about traditional interpersonal conflict resolution methods in the case of land in Arga and Asherakebele 16 in Simada Worda in the local community conflict resolution system was seen in this research study. Simadaworda Arga and Asherakebele the respondents of this research activity, from the total household 75 was selected, from those household 45 males and 30 females was selected based on sampling point. From sampling fighter 25 was selected, from those male 17 female 8 , official experts was 24 , from those 16 male and 8 female. From total respondent were selected 124, from those 78 males and 46 female. Most of the respondents result indicated that conflict arising by using inheritance problems from males $24.3 \%$ (19) and females $19.56 \% \%$ (9), then problem related to boundary conflicts $34.6 \%$ (27 male and 16 female).
\end{abstract}

Keywords: Simada Worda; Arga; Ashera; Inheritance; Incompatibility; Traditional; Transparency

\section{Background of the Study}

Conflict is fundamental and predictable part of human existence. It is a condition of disharmony in an interactional process, and represents part of the dynamics of the relationship between human beings [1]. It is an interactive process manifested in incompatibility, disagreement, or dissonance within or between social entities Rahim [2], in which one party perceives that its interests are being opposed or negatively affected by another party [3]. Conflict is the misbehavers of the peoples and breaking down of low where some time it's even it grows for civil war and unstable and also conflict decreasing the growing of development in the country for this reason conflict also stand up for the peoples will dies.

According to Kbele community policing services report many peoples fighting in the cause of land. So the cause of conflict were peoples fighter with in the bordered of land and lack of manpower skill development in the Kebeles. If the awareness the land this is my land if the fighter said that in the cause peoples fighter with other peoples. Land is useful for peoples of the Kebeles and land is an incoming the economical production basic need and row materials and building infrastructures in the land owner of the peoples. One of the mechanism of conflict resolution methods every peoples or citizen to be should peace keeping process. Because of there is no conflict or if there's peace keeping process there's is sustainable development's and also increase GDP of the country and also increase GDP of the world Glop.

In Simadaworda especially Arga and Asharakebela at the current times interpersonal conflict in land very common in local community living this Kebles. Because of land of non-renewable resources, and also these resources very essential to rural livelihoods are highly improving incomes generating activity by different crops growth, as one of the settlements purpose and other. So that land conflict is increasingly time to times, this problems going to for un peace building, not conflict prevention, and longer-term social-ecological flexibility (Figure 1).

Alongside the more traditional recognition of the importance of common-pool resources in reducing poverty and building rural people's assets is an emerging awareness of the positive potential that cooperation around natural resource challenges can offer in reducing the risk of broader social conflict and violence. While this rationale is not altogether new among advocates of public policy support for and investment in natural resources management [4], it is gaining traction in international development circles DFID [5], as well as in the environmental conservation and peace building communities $[6,7]$.

Simadaworda one of the south Gondar zones, especially this worda different types of conflict raising the rural community in those Kebele the past time up to the current times. In addition to this problem most of the farmer negative altitudes in other peoples, the government lack of transparency about some of issues or lack of good governess and lack of moral behaviors. The study was assessing the perception of the peoples around interpersonal conflict in land property.

Peace keeping practices the only mechanism to avoid the conflict in the Kebeles. Peace is available in the Kebeles to manage the conflict to raising interpersonal conflict and people's conflict.

The main objective of the study is to assessing interpersonal conflict in the cause of land conflict in Semadawerda, Kebela Arga and Ashara.

The main concern of this research, the assess interpersonal conflict in the cause of land conflict in Semadawerda. The study conducted Semada Worda, it bring change the following pointes. How to Help to official of the Kebela local community how to encourages and support those peoples and as sources of information and research ideas on interpersonal conflict what are the causes. In addition to this the study had outcome to help the local community policy and Simada/ Kebeles benefits from the information to identify interpersonal conflict problems encountered. How to stop interpersonal conflict in the Kebela. The researcher helps and addresses the problem and case and to reduce the fighter or crimes in the Kebeles and to rises the peace's keeping process.

*Corresponding author: Abay Bantihun, Faculty of Agriculture and Environmental Sciences, Debre Markos University, Deber Tabor, Ethiopia, Tel: +251-0- 9100279 21; E-mail: abay2113@yahoo.com

Received November 07, 2017; Accepted November 14, 2017; Published November 21, 2017

Citation: Bantihun A, Worku M Inter Personal Conflict Resolution Methods on Case of Land in SemadaWerda, South Gonder Ethiopia. Arts Social Sci J 8: 315. doi: 10.4172/2151-6200.1000315

Copyright: (c 2017 Bantihun A, et al. This is an open-access article distributed under the terms of the Creative Commons Attribution License, which permits unrestricted use, distribution, and reproduction in any medium, provided the original author and source are credited. 


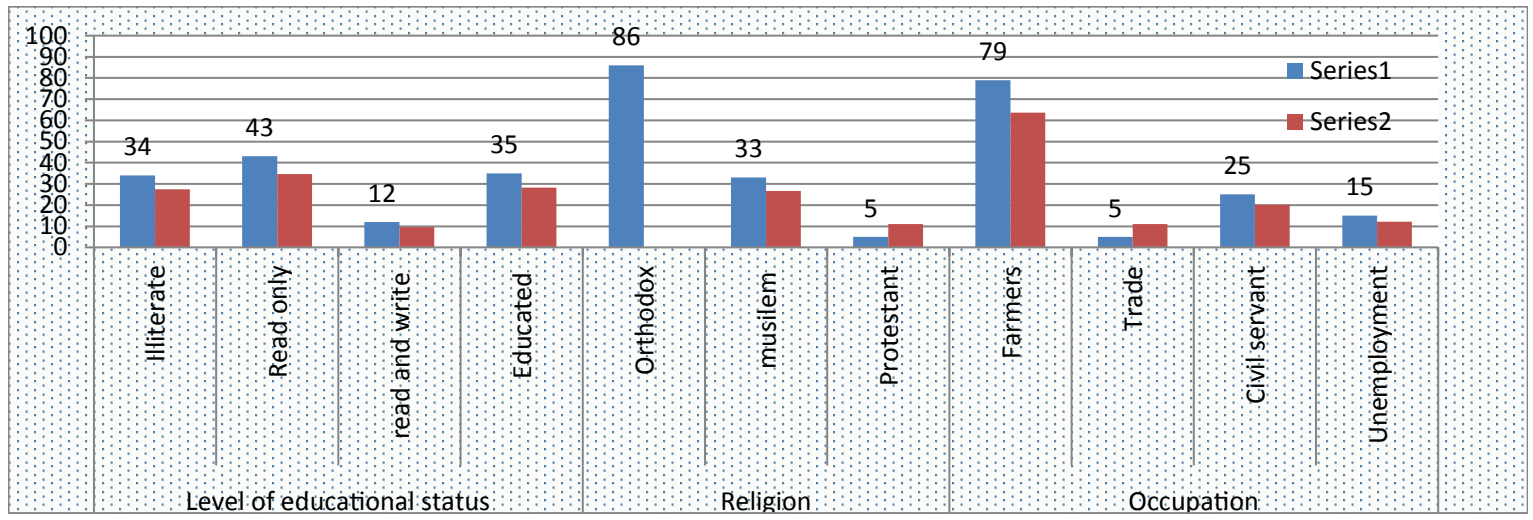

Figure 1: Level of education, religion and occupation of the Respondent.

\section{Research Methods and Methodology}

\section{Research design}

This research was carried out in Simadaworda especially Arga and Asherakebele to meet the research objectives a household survey assessment was conducted in selected randomly households, select official experts and fighter. In household survey questionnaires with open and closed ended questions was developed to collect the required information. The socio-economic data like the household age, sex, education level, family size, size of farm land was collected. In this study qualitative and quantitative data was collected to meet the research objectives. Both qualitative and quantitative research methods were used. The rationale of use the mixed method is that using fully solves the research problem and the objectives to be achieved.

\section{Description of the study area}

Simada is located in South Gondar Administrative Zone, Amhara Regional State. It is one of the 11 administrative Weredas of South Gondar Zone. It is divided into 40 Kebeles, 1 town and 39 rural Kebele administrations. The seat (capital) of Wereda administration is Wogeda which is located at $105 \mathrm{~km}$. distance southeast of the zonal capital Debre Tabor and found at about $205 \mathrm{~km}$. Distance away from the regional capital Bahir Dar and at $770 \mathrm{~km}$ distance from Addis Ababa. Simadawereda boarders in the north with TachGaint and Lay Gaint weredas, in the south with East Gojam's Enebse Sar Midir wereda, in the east with South Wollo's Amhara Saint and Mekdela wered as and in the west with Este wereda of South Gondar Zone.

\section{Sources of data}

Sources of data or information about this research were used primary and secondary data sources. Primary data the information obtain from respondent from questioner, interviews and observation was selected sampling.

Secondary data were obtained largely through the analysis of various documents relevant to the study from both published and unpublished documents. This includes institutional annual reports (SimdaWorda/Arga and Asherakebele administration and office, community policies), manual reading, books, records, and journals/ papers/articles which provide baseline information for the study.

Primary data were collected through household questionnaire survey using structured questionnaires with both open-ended and closed-ended questions, focus group discussion, it composed of elders, church community, leader, youth and landless household heads. Secondary data was taken from institutional reports, interview to prepare by using checklist, field observation and survey, while secondary data were collected through documentary review. The aim was to cross check and verify information obtained through these different methods regarding the topic in question. The target group for this study was all farmers in the Simadaworda Arga and Asherakebele.

Interview: The interview was also used as tool to capture the general overview of the identify interpersonal conflict views of different stakeholders and practice toward the Simadaworda Arga and Asherakebele. To selected community elders, Agricultural experts, land administer and community office. The entire interviewed individuals were above eighteen years of age.

\section{Observation}

Before the actual research work and data collection, an observation survey was conducted to have a general overview of the research sites, the livelihoods of the community, and the conditions in the study area. The reconnaissance survey was help to refine the data collection methods, to have sufficient information gain questionnaire development and to trace secondary materials.

\section{Sampling methods and techniques}

To conduct this study the researcher used sampling methods sampling techniques using simple random methods. The researcher methods more appropriate to gathering information with Simadaworda specially Arga and Asherakebele by using questioner and interview from the selected sampling. The researcher employs survey type of research because it uses scientific sampling and questionnaire design to measure characteristics of the population with statistical precision. The sampling unit was the household. A household in this study is referred to as a basic unit of production and consumption, made up from the persons who farm common fields and live under one central decision maker, the household head. The overall sample size was determined by the method proposed by Bartlett et al. [8]. Therefore, in order to determine the sample household size for each Kebeles, the researcher was applied proportional sampling formula Arga and Asherakebele.

$$
n_{i}=\frac{n\left(s_{i}\right)}{N}
$$

Where:

\section{$\mathrm{n} \_\mathrm{i}=$ samples size of each Kebele}

$\mathrm{n}=$ total sample size of the study; 


\section{s_i=Total households of each kebele;}

$\mathrm{N}=$ total number of households in all sample Kebele,

General characteristics of respondents: The economic levels of the respondents in the study area were poor, medium and rich and socially they are inter related, because most of respondents were farmers, which depend on agricultural practices while some respondents are employed in governmental worker, small merchants who were benefited from the sailing Agricultural product either directly or indirectly way.

Simadaworda Arga and Asherakebele the respondents of this research activity, from the total household 75 was selected, from those household 45 meals and 30 females was selected based on sampling point. From sampling fighter 25 was selected, from those male 17 female 8 , official experts was 24 , from those 16 male and 8 female. From total respondent were selected 124 , from those 78 males and 46 female (Table 1).

\section{Methods of analysis}

Household survey data was analyzed by descriptive statistics (such as frequency, percentage), socio-economical characteristics of households, summarized by using tables and graphical presentations.

\section{Result and Discussion}

\section{Exploring land conflict in Ashera and Argakebeles}

Cause of land conflict in the Kebeles: Land is of principal importance to most local community in the Simadaworda especially in Arga and Asherakebele. Land is more than just lands because of a real economy in the country depend on land like agriculture expansion that grow their subsistence crops, rural settlements explanation. This is where people disputes land-related conflict is common throughout history in the Simdaworda most other human societies depend on agricultures is the backbone of cash incomes in the local community.

The main causes of conflict according to the data indicated that Arga and Asherakebele conflict arise land system is based on land administration disputes, conflict in land tenure, ownership disputes and boundaries disputes as one of common. Interpersonal conflict can be located between customary owners and the government or between customary owners.
Most of the respondents result indicated show that in Arga and Asherakebele (Table 2) indicated that conflict arising by using inheritance problems from males $24.3 \%$ (19) and females $19.56 \% \%$ (9), then problem related to boundary conflicts $34.6 \%$ (27 male and 16 female) are probably the most common land conflicts are more specific and predominantly occur in either.

These types are: land administration disputes, inheritance conflicts and ownership disputes and disputes over boundaries [9]

Location of the boundary: the main contradiction emerges as a result of competition over a farm land across the border. A position is understood as are source that cannot be shared. This is because only one person at a time cans hold given position. The position in question might be that of chief executive in Arga and Asherakebele. One approach to dealing with conflicts over boundary positions, especially in cases where the conflict parties are competing over who should legitimately govern a state (Table 2).

This extract implies that although conflict may be caused by various factors, here is one thing that many people may agree, that is the source of many conflicts are taking advantage of other people, divergences of interests or obtaining varying perceptions and thoughts or feelings. The respondents explained the term conflict in the way they understand.

Sources and consequences of conflict: According to the data indicated that areas there are also different sources of conflict in local community Arga and Asherakebele. The researcher questioned informants result indicated what could be the main sources of conflict in community is occurs between or among the youngsters. In farm land conflict between two neighbor. The farm lands because of the categorized under the source incomes.

Similarly, Fisher states economic conflict involves competing motives to attain scarce resources. The other one that is categorized under the power conflict since both persons in conflict attempts to maintain or maximize the amount of influence that it exerts in the relationship and in the social setting.

As Desalegn [10] explains, natural resources-based conflicts are part of the fabric of local communities as individuals compete for scarce resources: social groups perceive themselves as having incompatible

\begin{tabular}{|c|c|c|c|c|c|c|}
\hline Ketena & To no of population & Sampling HH point & Total no of fighter & Sampling of fighter & Total officially & Sampling officially \\
\hline 1 & 800 & 9 & 5 & 3 & 5 & 3 \\
\hline 2 & 950 & 11 & 7 & 4 & 5 & 3 \\
\hline 3 & 200 & 6 & 4 & 2 & 5 & 3 \\
\hline 4 & 765 & 8 & 7 & 3 & 5 & 3 \\
\hline 4 & 940 & 10 & 6 & 3 & 5 & 3 \\
\hline 6 & 630 & 7 & 5 & 2 & 5 & 3 \\
\hline 7 & 725 & 8 & 9 & 5 & 5 & 3 \\
\hline 8 & 1200 & 16 & 6 & 3 & 5 & 3 \\
\hline Total & 6210 & 75 & 49 & 25 & 40 & 24 \\
\hline
\end{tabular}

Table 1: Sampling point from each ketene.

\begin{tabular}{|c|c|c|c|c|c|}
\hline \multirow[t]{2}{*}{ No } & \multirow[t]{2}{*}{ Cause of conflict } & \multicolumn{2}{|c|}{ No respondent } & \multicolumn{2}{|c|}{ Percentages (\%) } \\
\hline & & Male & Female & Male (\%) & Female (\%) \\
\hline 1 & Boundaries conflict & 27 & 16 & 34.6 & 34.78 \\
\hline 2 & Inheritance conflicts & 19 & 9 & 24.3 & 19.56 \\
\hline 3 & Land administration disputes & 11 & 6 & 14.1 & 13.04 \\
\hline 4 & Ownership disputes & 14 & 7 & 17.9 & 8.95 \\
\hline \multirow[t]{2}{*}{5} & Other & 7 & 8 & 8.95 & 17.39 \\
\hline & Total & 78 & 46 & 100 & 100 \\
\hline
\end{tabular}

Table 2: The main cause of land conflict in the Kebele. 
interests. According to some informants, interpersonal and role conflict seems common in this community. However inter group conflict are not. This is so, as it is mentioned below by an interviewee.

The impacts of land conflict in the community: There are many different impact of conflict in Arga and Asherakebele. These according to the respondents data indicated that can include clashing material interests, a lack of material benefits, differences in identity, ideological or spiritual outlook, stereotypes and prejudices, frustrations with interpersonal relations, or a lack of knowledge, skills and experience for overcoming differences.

Identifying and understanding the possible causes of a conflict is essential to dealing with it effectively, and is a key part of conflict analysis. From the according to data indicated that different kinds of people that perceived in different ways. In the following table we look at some of the impacts. One of the in depths interviewees informants explains to the question, what does conflict. The informant responded that "Conflict is a clash of ideas between or among friends, neighbors, family. It can also be among or between people. The source of this conflict might be difference of interests. Similarly, respondent emotionally damaging risks 45\%, un coherence of expression Psychological and emotional $55 \%$. Isolation from peers or family conflict as follows.

Institution mechanisms to resolving the conflicts: The data obtained from interviews result also showed that conflict resolve processes can be classified in regards to theirformal and informal conflict resolution. Informal processes or traditional resolution that rely little formal but follows the norms, custom and local culture local community example everyday negotiations.

In any social structure, conflicts are arisen over different opportunities for an adequate reward. For all these conflicts happen we have conflict resolution methods. Conflict resolution methods may include negotiation, mediation and arbitration. Negotiation is a conflict resolution method by dialogue or discussion between two parties.

Mediation refers to a conflict resolution method on which decisions are not given. "Although it still allows disputing parties considerable flexibility in reaching a resolution, mediation is quite a bit more structured and formalized than general negotiation because it employs a neutral, third-party mediator to assist the parties with reaching a consensual agreement [11]. Whereas, arbitration is a way of setting a conflict on which the third party is involved and gives decisions. After reviewing evidence and hearing arguments from all interested parties, are given the power to impose their determination as to how a dispute should be resolved. The Kebele law court uses to minimizing the interpersonal conflict in case of land disputes. In the disputes over land are determined by the of the High Court, which investigates titles and determines the relative interests of owners of customary title.

If the court makes an order in favor of a person or persons that results in the vesting of an estate in the person or persons, the land then ceases to be customary land and becomes native freehold land. The result indicted that informal process by using negotiating very useful view of minimizing interpersonal (Table 3). A good conflict manager must be responsive and be able to see if anyone in the group is happy. It important and create good atmosphere among the local community members [12].

Local institution: Simadaworda in Arga and Asherakebele the respondents of this research activity, Local institutional that are reduced land conflict can occur stable peace's. According to respondents the local institutions the $15.4 \%$ religion administrative has the capacity to resolves the land conflict in the Kebeles, but the majority of the respondents to resolves the conflict by using land administration Expertise at list $42 \%$ (Table 4 ).

\section{Factor affecting land conflict}

Simadaworda in Arga and Ashara kebela the respondents result indicated that factor affecting land conflict, most of the respondent says Political causes economic factors, Socio-economic causes and Sociocultural the respondents list down.

Political causes one the factors, from those changes in the political system, including Derg regimes up to current system polices in land system also changes time to times, some of the political corruption. And also support for big farmers to the disadvantage of poorer peasants and from the economic factors or point of view like increasing

\begin{tabular}{|c|c|c|c|c|c|c|}
\hline \multirow[t]{2}{*}{ No } & \multirow{2}{*}{\multicolumn{2}{|c|}{ Conflict management }} & \multicolumn{2}{|c|}{ No respondents } & \multicolumn{2}{|c|}{ Percentage (\%) } \\
\hline & & & Male & Female & Male & Female \\
\hline \multirow[t]{4}{*}{1} & \multirow[t]{4}{*}{ Formal } & Kebele low court & 23 & 13 & 29.48 & 28.26 \\
\hline & & Worda court & 16 & 9 & 20.51 & 19.56 \\
\hline & & Zone court & 9 & 5 & 11.53 & 10.86 \\
\hline & & Regional court & 3 & 2 & 3.84 & 4.34 \\
\hline \multirow[t]{3}{*}{2} & \multirow[t]{3}{*}{ Informal } & Negotiations & 9 & 8 & 11.53 & 17.39 \\
\hline & & Mediation & 8 & 4 & 10.25 & 8.69 \\
\hline & & Arbitration & 7 & 3 & 8.97 & 6.52 \\
\hline \multirow[t]{2}{*}{3} & \multicolumn{2}{|l|}{ Other } & 3 & 2 & 3.84 & 6.52 \\
\hline & \multicolumn{2}{|l|}{ Total } & 78 & 46 & 100 & 100 \\
\hline
\end{tabular}

Table 3: Conflict managements strategic.

\begin{tabular}{|c|c|c|c|c|c|}
\hline \multirow[t]{2}{*}{ No } & \multirow[t]{2}{*}{ Local institution } & \multicolumn{4}{|c|}{ Number of interviewed individuals } \\
\hline & & Male & Female & Male \% & Female \% \\
\hline 1 & Religion administrative & 12 & 10 & 15.4 & 21.7 \\
\hline 2 & Local elder & 16 & 8 & 20.5 & 17.4 \\
\hline 3 & Land administrative Expertise & 33 & 23 & 42.3 & 50.0 \\
\hline \multirow[t]{2}{*}{4} & Community polices & 17 & 5 & 21.8 & 10.9 \\
\hline & Total & 78 & 46 & 100 & 100 \\
\hline
\end{tabular}

Field survey (2017).

Table 4: The impact of local institution reduced conflict. 
land prices. Socio-economic causes like Poverty and poverty-related marginalization, extremely unequal distribution of power and resources (including land), Lack of microfinance options for the poor. Socio-cultural causes destroyed or deteriorated traditional values and structures,rejection of formal institutions (new, foreign, external), low level of education and lack of information on institute and mechanisms of land markets, High potential for violence and Abuse of power.

\section{Effect of land conflicts}

Simadaworda in Arga and Ashara kebela the respondents result indicated that land ownership conflicts have negative effects on individual households as well as on the nation's economy. They increase costs, slow down investment, can result in the loss of property for a conflict part and reduce tax income (land tax, trade/commercial $\operatorname{tax})$ for the state or municipality. The lower the transparency in land markets, the less equal is information being disseminated, and the weaker constitutive and regulatory institutions are, the more likely it is that land conflicts occur. People therefore need to spend a lot of time and money on searching for information and monitoring agreements/ contracts. This means that land conflicts are associated with high transaction and agency costs or vice that (relatively) high transaction and agency costs indicate a high probability of land conflicts.

\section{Conclusion}

This research was carried out to assess the intrapersonal conflict on land issues related conflict in Simda Worda communication of Arga and Asherakebele. To conduct this study, the researcher employed the qualitative, quantities and mixed methodology was implemented. Focus group discussions, in depth interview and participant observation were used to obtain the necessary data from the sample respondents in kebele namely Arga and Ashera. On this research observed at various scholarly articles related to interpersonal conflict related to land. This research was identifies different interpersonal conflicts in land in the Simada Worda in Arga and Asharakebela some of the problem that are lack of a clearly defined land policy, particularly lack of effective recognition for and protection of the customary land rights, has inturn resulted in over land since multiple 'stakeholders' with varying interests, sources of legitimacy and values have come into play to exercise claims over land, often leadingto conflicts. The study also revealed that in the formal and informal conflict resolution mechanisms to reduced land resources conflict Arga and Ashara local community.

\section{Recommendations}

As the study signifies community's social, cultural and economic affairs, therefore due attention need to be given by the concerned bodies such as the community land conflict resolution in kebeleArga and Ashara in Simada Word. The data collection tools were used participant observation, individual in depth interview, questioner and focus group discussion. The researcher employed the participant observation personally to observe the social, cultural and economic affairs on land conflict. Focus group discussion was used to obtain enough information about land conflict and resolution mechanism. Other than these, the researcher used the individual in-depth interview to get detailed data about the subject. The selection of the interviewees was based on their in-depth knowledge about conflict resolution and promoting democracy was raised.

\section{References}

1. Imobighe T A (1995) Nature of conflicts Paper presented at the seminar on confmanager organized by the African Leadership Forum/Academic Associates Ibad Nigeria.

2. Rahim M A (1992) Managing conflict in organizations New York: Praeger.

3. Wall JA, Callister RR (1995) Conflict and its management. Journal of Management 21: 515-558.

4. Tyler SR (1999) Policy implications of natural resource conflict management in cultivating peace.

5. DFID (2007) Preventing Violent Conflict London: Department for International Development.

6. Feil M D, Klein, Westerkamp M (2009) Regional Cooperation on Environment Economy and Natural Resource Management: How can it contribute to Peace building Brussels: Initiative for Peace building.

7. UNEP (2009) From Conflict to Peace building: The Role of Natural Resources and the Environment Nairobi Kenya, United Nations Environment Program.

8. Bartlett J E, Kotrlik J W, Higgins CC (2001) Organizational research: determining Appropriate Sample Size in Survey Research Information. Technology Learning and Performance Journal 19: 43-50.

9. Fonmanu KR, Ting L, Williamson IP (2003) Dispute Resolution for Customary Lands: Some Lessons from Fiji Survey Review 37: 177-89.

10. Desaleg (2005) Haramaya University Ethiopia International Water Management Institute (IWMI)ILRI-Ethiopia. campus Addis Ababa Ethiopia.

11. Deacon D (2009) Researching Communications Arnold: London .

12. Adams M (2010) Effective methods of alternative dispute resolution: Negotiation mediation and arbitration. 